\title{
A poética do convite e as performatividades trans/formativas.
}

\section{An inviting poetics and trans/formative performativities.}

\author{
Janaína Moraes \\ Universidade de Brasília | Brasília, DF, Brasil. \\ jana1504@gmail.com I ORCID: https://orcid.org/0000-0001-6910-8691 \\ DOI: $10.20396 /$ conce.v8i2.8656067. \\ Submetido em: 27/07/2019 | Aceito em: 17/11/2019 | Publicado em: 20/12/2019.
}

\section{Resumo}

Nesse escrito compartilho reflexões sobre uma Poética do Convite enquanto agenciadora de campos de performatividade trans/formativa. Trans/formação enquanto PALAVRAS-CHAVE Poética do convite. Performatividade. Trans/ as formações que se dão no trânsito. Lugar de passagem. Deslocamento. Ser artista, educador/a, pesquisador/a. Estudante, investigador/a. O ensino, a criação. A prática, a teoria. Transicionando por jornadas autônomas embora compartilhadas. Assim, aponto desafios de operar po/eticamente na perspectiva das querências compartilhadas.

\section{Abstract}

In this article I share a few thoughts about an inviting poetics as the agent for trans/formative fields of performativity. Trans/formation as the formation KEYWORDS Inviting poetics. Perfomativity. Trans/ which takes place in transit. Transitory places. Sense of displacement. Being an artist, an educator, a researcher. Student, investigator. The teaching, the creating. The practice, the theory. Transitioning through both autonomous and shared journeys. Thus, I point out some challenges of po/ethically operating in the viewpoint of shared desires. 
O que separa o fazer do pensar? Quando é ensino, mediação, provocação? O que diferencia estudante de artista investigador/a? E educador/a de criador/a, e de pesquisador/a? Que relações se estabelecem a partir de como me estabeleço? Quais instâncias de poder se articulam quando (me) coloco em (oper)ação? O que pode e quem pode? Essas perguntas e suas variações me acompanham há alguns anos no trânsito entre a "sala de ensaio" e a "sala de aula". Reconheci-me artista quando em minha jornada de licenciar-me professora de dança e, nesses mais de seis anos de carreira, foram raras as vezes em que de fato pisei em uma escola para conduzir aulas de dança.

Em meus percursos já passei por companhias, grupos e coletivos artísticos. Já estive bailarina, diretora, dançarina, professora, pesquisadora, coreógrafa, educadora, artista-criadora, intérprete, performer, provocadora... Hoje entendo-me uma ajuntadora de querências no que tenho nomeado de ajuntamento artístico "Abrindo a Sala". A necessidade de encontrar outros modos de chamamento ${ }^{1}$ tem muito a ver com a vontade de precisar as éticas de trabalho propostas pelo que tenho investigado enquanto uma Poética do Convite ${ }^{2}$. A ideia de ajuntamento, portanto, propõe criações elaboradas por comunidades temporárias que se juntam para realizar acontecimentos específicos.

Nessa poética tenho visitado muito frequentemente as contradições da prática artística, formativa e performativa que, em seus paradoxos, parecem constantemente criar e deslocar sfumatos ${ }^{3}$ que confundem contextos criativos, educativos, artísticos, ora em fusão, ora em confusão. Por vezes uma overdose de palavras-mundo esquecidas sendo acionadas para descolar percepções e, assim, aguçar sensações. Por vezes, um mergulho profundo sobre a aridez de palavras-conceito que se esvaziam para ampliar espaços e tempos relacionais, sinestésicos, poéticos. Tenho visitado (e por vezes habitado) a potência do não saber enquanto geradora de conhecimento marginal e legítimo.

É importante mencionar que não busco menosprezar as particularidades e diferenças necessárias às diversas práticas pedagógicas em artes que se separam de práticas artísticas. No entanto, proponho uma contribuição que visa a

\footnotetext{
${ }^{1}$ Chamamento: o nome que se dá. Chamamento: o convite que se faz para "estar participante de".

'Em sua etimologia, a palavra convite vem do latim invitare, com a troca do prefixo in-, "em", por com-, "junto", mais o desaparecido verbo vitare, significando "querer" (troca que teria se dado sob a influência de convivium, "banquete"). Ou seja, convidar é querer junto.

${ }^{3} \mathrm{O}$ sfumato é uma técnica artística usada para gerar suaves gradientes entre as tonalidades, comumente aplicada em desenhos ou pinturas. Vem do italiano sfumare, que significa "de tom baixo" ou "evaporar como fumaça". Não apenas uma técnica, mas um recurso que "desendurece" os contornos e consequentemente "ameniza" a expressão humana.
} 
problematizar um ensino de arte que se isole da prática artística e seus modos de pensar. Em minhas práticas, não consigo mais desvincular o ato de criar do ato de ensinar. Ainda: não vejo possibilidade de ensino sem aprendizagem. E esse, em minhas criações, é nosso chão comum: estamos em criação, potencialmente ensinamos e sempre temos o que aprender. No mais, "acredito em caminhos de pesquisas em que o corpo, quando aprende, o faz criando" (TRIDAPALLI, 2008, p. 12).

Nessa lógica, proponho algumas trans/formações epistemológicas a partir de duas perspectivas: estamos cada vez mais distantes da lógica de paradigmas e caminhando para uma lógica de paradoxos (VILLAR, 2013); e o ensino (dentro do escopo desse artigo, o ensino artístico) necessita ocupar-se cada vez mais de jornadas autônomas de des/aprendizagem - deslocamento da aprendizagem como uma prática de trans/formação: formação que se dá em trânsito.

Para trilhar essa proposta, seguro nas mãos de algumas pessoas. A primeira delas é Cindy Foley, Assistente de Direção Executiva e Diretora de Aprendizagem e Experiências no Museu de Arte da Columbus. Em palestra no TEDxColumbus (2014), Foley apresenta algumas problematizações do ensino de arte das quais lanço mão para a construção das discussões aqui propostas. Convido-lhe, leitor/a, a acompanhar o pensamento de Foley traduzidos (talvez traídos) em minhas palavras e reorganizados a partir das proposições dessa poética aqui compartilhada.

Durante o ensino de dança, muitas vezes nos percebemos dando enfoque em conteúdos como: elementos de arte, história da arte, habilidades e técnicas fundamentais - essencialmente coisas que podemos testar e avaliar. Porém, e se nos dedicássemos a ensinar des/aprendizes a pensarem artisticamente? Aqui provoco que des/aprendiz é qualquer pessoa que deseja aprender permitindo-se deslocar aprendizagens. Oxigenar pontos de vista, insistir, repetir, desistir, reexistir, trans/formar percepções.

Levanto, assim, uma primeira possibilidade para a trans/formação - $a$ formação no trânsito entre o que já sei e o que posso vir a saber quando permito o não saber. Voltamos nossas abordagens para a provocação de aprendizes que sejam curiosos e criativos, que questionem, desenvolvam ideias confiando na diversão e no desejo como guias para pesquisas autônomas. Nesse sentido, a prática da Improvisação em Dança, nessa perspectiva epistemológica na qual a 
poética do convite tem se desenvolvido, é um caminho potente para preparar-nos aptos ao não saber. Aqui seguro as mãos de outra artista e filósofa, Erin Manning (2016), que ao falar da Improvisação em Dança e seus mínimos gestos, considera

movimento como decisão (...) Decisão aqui definida não como externa ao evento, mas como o recorte no próprio evento, por meio de novas ecologias, novos campos de relação são criados. (...) Movimentos não conscientes são decisivos no sentido que são capazes de alterar o curso do evento durante o próprio evento. Chamei a sintonização, no evento, rumo ao movimento decisional, de pensamento coreográfico, enfatizando a habilidade que o movimento tem de recortar e alinhar tempo-espaços de composição em caminhos que abrem experiências para novos registros. (MANNING, 2016, p. 19.)

Proponho que a Improvisação em Dança na Poética do Convite leva em consideração que, ao receber um convite, temos a possibilidade de aceitá-lo, recusá-lo ou contrapropor outros convites. Seja qual for a opção escolhida, ao abrir o espaço para vias de mão dupla, "o evento envolve performers e espectadores em atmosfera compartilhada e espaço comum que os enreda, contamina e contém, gerando uma experiência que ultrapassa o simbólico" (FERNANDES, 2011, p. 17). Mais do que signos e sentidos, passamos a construir realidades, compartilhando experiências.

Costurada a essa instância trans/formativa do não saber enquanto um saber próprio, aponto uma segunda, que é a formação no trânsito entre o desejo pessoal e o desejo coletivo. O desafio aqui é identificar interesses pessoais (o que move) ao mesmo tempo que reconhecer interesses coletivos (o que comove). Como propõe Marina Garcés (2013), engajar-se nessa descoberta que é

individual e coletiva: é irredutivelmente sua própria e, ao mesmo tempo, diz respeito aos outros. Ocorre em uma relação paradoxal entre a felicidade do encontro e a solidão radical, entre a aparência de preocupações compartilhadas e a necessidade de assumir suas consequências da própria vida. Não posso dizer onde minha voz começa e acaba com a de outros. Eu não quero saber. É minha maneira de agradecer a presença, em mim, do que não é meu. (GARCÉS, 2013, p. 10.)

Vale ressaltar que um dos pontos-chave na ideia poética do convite é a constante autorreflexão que sua essência sugere: ao convidarmos, submetemos nossas proposições à genuína vontade da outra pessoa na qual e como se dá sua participação. Interessam ao convite as constantes negociações e diálogos que se estabelecem nos processos de criação e apreciação de uma experiência artística. Quando nos abrimos para o convite, colocamo-nos diante de tomadas de posição no aqui e agora. Trata-se de constantes proposições ao engajamento entre criadores espectadores ${ }^{4}$ e a própria obra que é criada a partir dos 
encontros: por meio do convite pode-se "promover uma experiência através da qual conteúdos são elaborados" (FABIẪO, 2008, p. 243), possibilitando-nos discussões sobre poéticas e políticas de produção e recepção de artes cênicas contemporâneas.

Desse modo, é na atenção entre essas querências compartilhadas que a Poética do Convite se instaura por meio da ética do que é transitório, dinâmi$\mathrm{co}, \mathrm{co} /$ movente... A possibilidade de des/estruturar, deslocando e reconfigurando estruturas a cada encontro e a partir de cada contexto. Exercitar a habilidade de re/fazer conexões. Essas conexões nos apontam para a necessidade de nos relacionarmos com outros tipos de percepção, com outros modos de conhecimento. A possibilidade de articular e compor contextos sem evitar as contradições e ambiguidades. Mergulhar no que perece sem se desvincular da responsabilidade sobre o que (se) agencia. Fernando Villar (2013) propõe que

complementar às grandes áreas de conhecimento das Ciências e da Filosofia, a Arte singra por mares de criação que deveriam estar livres de paradigmas excludentes, para navegar entre as maravilhas do paradoxo e do infinito de opções da poesia. Uma grande possível lição das Artes para as outras áreas de conhecimento e para nossas sociedades é a da possibilidade de convivência de poéticas diversas, opostas, contraditórias. (VILLAR, 2013, p. 2.)

Esse conforto com a ambiguidade abre caminho para que as dicotomias suavizem-se, evidenciando-se como especificidades que percorrem um dinâmico e movente spectrum de percepção. O que se organiza como resultado em um contexto pode configurar-se processo em outro. E é a capacidade de escutar os contextos junto à habilidade de jogar com eles que nos aproximam de práticas menos engessadas sobre o saber. O que faz um pensamento artístico é a capacidade de questionar: questionar o mundo naturalizado, questionar o modo de ver as coisas, questionar as políticas do tempo, os modos de operação e as éticas de trabalho. É sobre o potencial de re/configurar ideias a partir do que se é, está e tem. É sobre perceber os recursos ao redor (e nós somos também recursos) a fim de materializar ideias artísticas. A isto, em minhas práticas, tenho chamado de "materializações coreográficas", evidenciando minha perspectiva coreográfica diante das organizações artísticas pelas quais me empenho.

Materialização enquanto uma organização consciente de materialidades e(m torn)o (do) pensamento coreográfico. Um modo de entender-fazer com- 
posições coreográficas, as quais podem estar para além das estruturas mais convencionais de coreografia. Assim, pautada no pensamento coreográfico em contato com as mais diversas materialidades, uma materialização coreográfica seria uma composição atenta às especificidades de cada materialização, sempre ocupada em perceber que tipos de relação se criam com as escolhas acionadas. Essas estruturas podem se dar enquanto um espetáculo, uma performance, uma instalação coreográfica, uma colagem, um texto ou quaisquer outros formatos que possam situacionalizar acontecimentos. Entender essas estruturas como situações configuradas tem permitido deslocar e realocar contextos para a coexistência. Assim, ao compartilhar tempos e espaços re/configurados, visitamos relacionalidades (im)possíveis à composição coreográfica de/em cada acontecimento estético.

Ao facilitar tempos e espaços em que pessoas sintam-se confortáveis a permitir a ambiguidade como terreno onde os interesses e ideias conduzam a des/aprendizagem ${ }^{5}$, os interesses e ideias podem ser catalisadores para investigações pautadas na curiosidade. Pesquisas que possam aprofundar seus conhecimentos sobre aquilo que lhes interessa. Isso nos leva a mais uma instância trans/formativa que a Poética do Convite me tem permitido desbravar: a formação que se dá no trânsito entre as múltiplas perspectivas de mundo, vulgo transdisciplinaridade. Foley (2014) aborda a transdisciplinaridade como pesquisas que servem às nossas curiosidades. Como seria utilizar os conhecimentos de distintas áreas a serviço de nossas ideias? Não é sobre educar todos para serem artistas, mas promover situações que provoquem as pessoas a pensar artisticamente, independente da carreira que escolham para viver. É sobre criar espaços de trans/formação em que ideias reinem e a curiosidade lidere. Como des/aprendemos criando e reinventando noções de coletivo ao debruçar nosso olhar no encontro com pessoas e na transdisciplinaridade de linguagens, formações e perspectivas de arte?

Com o Ajuntamento Abrindo a Sala, temos vivenciado essa perspectiva transdisciplinar ao criar constantes interfaces em nossas investigações sobre dança e/m outros contextos. Compartilho, como exemplo, a Residência Artística Alimentança, quando convidei uma nutricionista de Itajaí/SC para conviver por 10 dias junto a artistas da dança e performance e, assim, investigarmos o que a criação coreográfica tem em comum com a alimentação consciente.

${ }^{5}$ A partir daqui, é importante enfatizar que um campo de aprendizagem pode se dar em contextos formais ou não formais do aprender. Aprendizagem estética, ética, poética, política... O que se pode aprender e onde se pode aprender? 
Essa experiência é um bom modo de ilustrar uma situação em que a Poética do Convite tem se desdobrado, percorrendo pelas diferentes instâncias de formação em trânsito já apontadas aqui.

Em contexto de residência artística, colocamo-nos diante de um problema criado por nós mesmas em que, ao identificar um desejo compartilhado [dar a ver o que a dança e a alimentação consciente têm em comum], lançamo-nos diante do não saber, uma vez que sabíamos que esse cruzamento nos era necessário, embora (ainda) não soubéssemos o porquê.
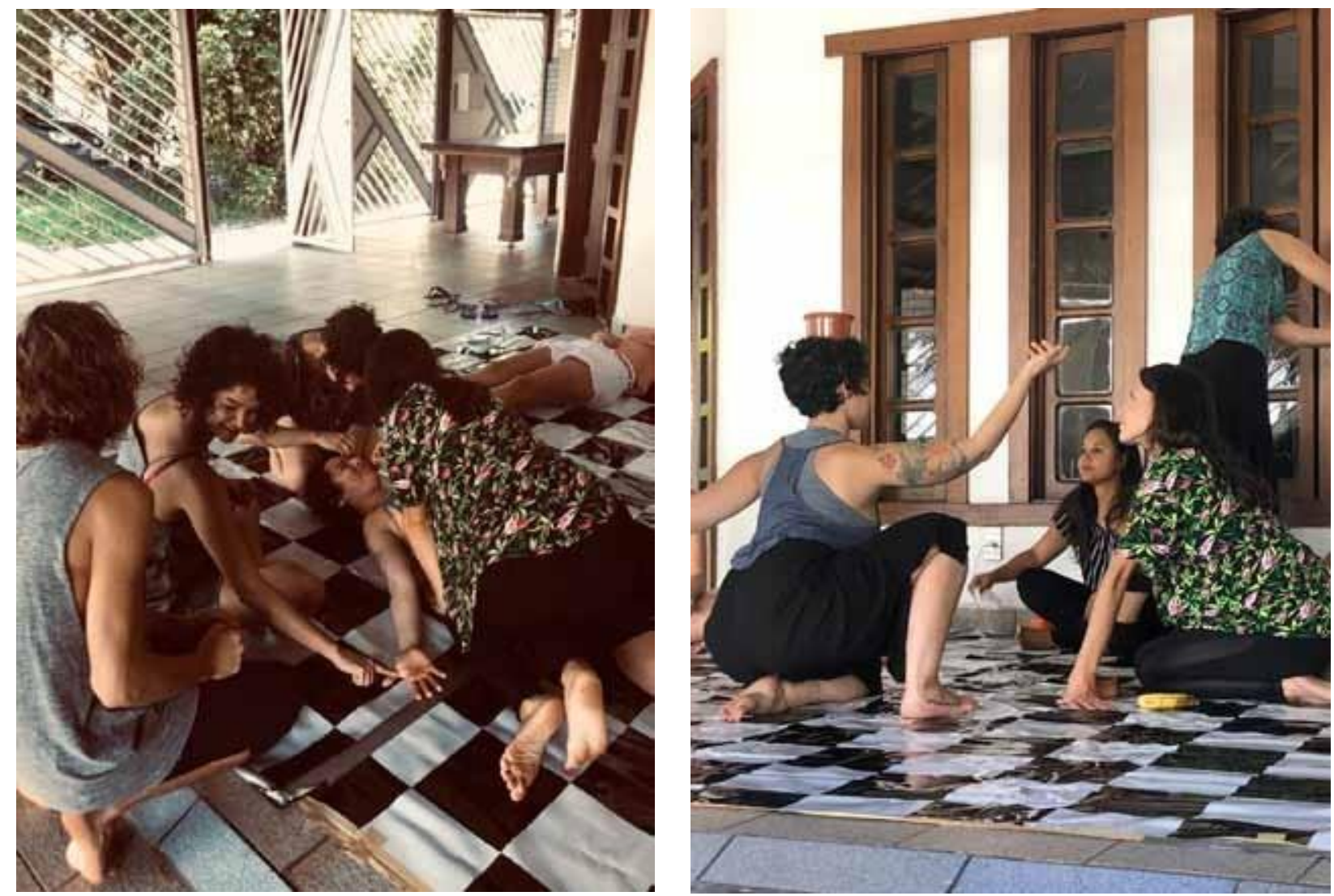

Figuras 1 e 2 - Investigações em Residência Artística Alimentança. Asa Sul, Brasília/DF, 2019. Fotos de Ingrid Beatriz.

Ao friccionar nossos modos de entender e lidar com o corpo e o alimento, investigamos percepções de arte e comida para além dos "processados". Percebemos juntas que se levantava a nós uma questão em comum: a dança, muitas vezes, vê-se reduzida a técnicas pré-concebidas ávidas por resultados maquiados pelas ideias do belo e saudável, desconsiderando a experiência integral e individual de cada corpo no ato de mover-se. O comer, por sua vez, tem se reduzido cada vez mais a uma prática consumista e ocupada em ser resolvida muito mais do que vivida. 
No entanto, comer é também uma experiência estética e política. Nossos interesses pessoais, identificados pelo encontro, acabaram por criar uma querência compartilhada por aquela microcomunidade temporária: o desejo de "reapetecer" os prazeres do corpo e do alimento integral. Com isso, levantaram-se também questões como: o que você come? Quais gestos te alimentam? Que indústria você alimenta quando escolhe sua comida? Como mover? Como pensar em um deslocamento tempo-espacial para que tanto o alimentar quanto o movimentar possam ser experiências amplificadoras da percepção e integração entre corpo, ser e o próprio alimento?

Assim, as questões éticas, estéticas e políticas suscitadas pela experiência de convívio em residência artística desembocaram na refeição-performance Diaita. Na interface entre arte e alimentação consciente, Diaita surge como um híbrido entre produto e experiência que se entende enquanto uma performance artística do percurso de cozinhar e comer. Tendo nascido em contexto de residência, acabou por se configurar também como um trabalho sítio-específico, reconfigurando-se a cada ambiente que passou a ocupar desde então. Uma outra evidência transitória que aciona é a possibilidade de mudar seu escopo ${ }^{6}$ a cada contexto (em) que (se) re/cria.
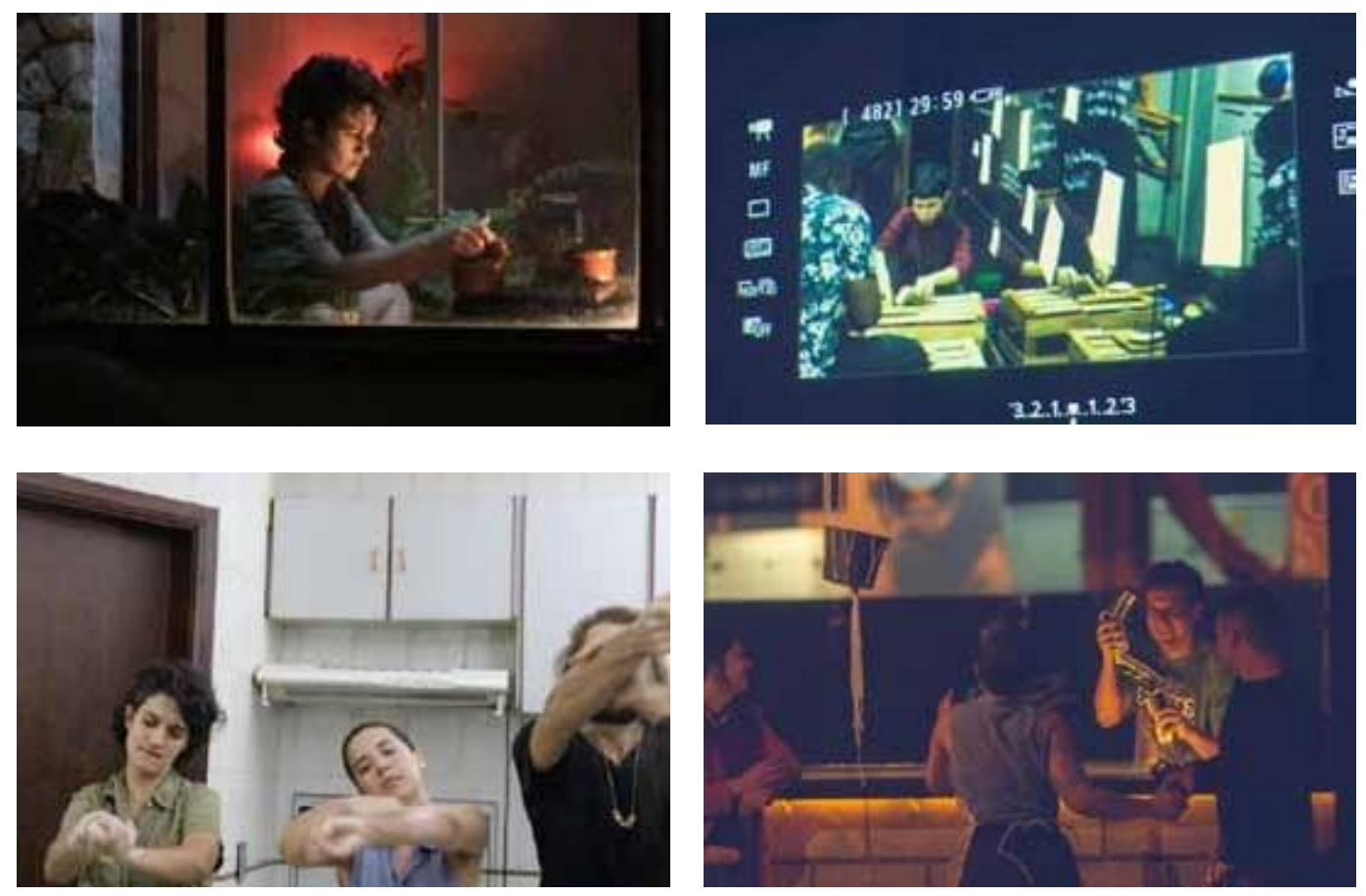

Figuras 3 a 6 - Sitio especificidade do espetáculo Diaita. À esquerda, em uma casa na Asa Sul. Fotos de Ingrid Beatriz. À direita, no bar Canteiro Central / Setor Comercial Sul. Ambos em Brasília/DF, 2019. Fotos de Humberto Araújo.

${ }^{6}$ Tanto escopo enquanto equipe - força humana que (é) aciona(da); quanto escopo enquanto estrutura formal do acontecimento - ações levantadas a partir do encontro entre o trabalho, as forças humanas e o próprio espaço. 
A cada apresentação a obra propõe um cardápio nutricionalmente pensado e artisticamente elaborado. A ação performática se estrutura sobre um programa-base de ações [pré-preparo, preparo, finalização e banquete] culminando na refeição como um ato poético. Para sua realização, ajuntam-se pessoas-criadoras-[não]artistas que se organizam no intuito de alargar percepções, deslocando modos de ver, fazer e pensar mundos (im)possíveis. Assim, no Diaita, o encontro se dá pelo convite de artistas do movimento a artistas da comida, juntando artistas, agricultores, nutricionistas e cozinheiras que elaboram refeições e/m performance. Um modo encontrado para engajar redes de colaboração a fim de visibilizar etapas e processos do alimentar-se.

Esse caráter transdisciplinar nos tem permitido experimentar fissuras em contextos [não]artísticos e nos proporcionado saborear a arte fora da arte, fora dos lugares comuns de "consumo de arte". A arte da horta e a arte da feira. A arte da cozinha de casa e a arte do restaurante. Cozinhar e comer como um ato ético, estético e político. Performativizar o ordinário ao invadir restaurantes e bares. Performativizar a refeição como modo de trazer consciência à alimentação e à arte. Sensibilizar questões que compõem os gestos do alimento, desde o plantar, colher, preparar, cozinhar, comer e devolver à terra.

A partir de uma estética que se constrói por meio de relacionalidades, compomos uma rede de ações que se co/movem para subsistir. Uma rede de que fazem parte produtores em diferentes escalas, cozinheiros/as, famílias, histórias e memórias, desde quem colhe até quem come. Ao convidar enquanto poética, nosso papel é aproximar essas pessoas, evidenciando (im)possíveis camadas po/éticas que movem esse ciclo de nutrição. Aproveitamos também para confundir arte e comida, coreografar alimentos e alimentar coreografias. 

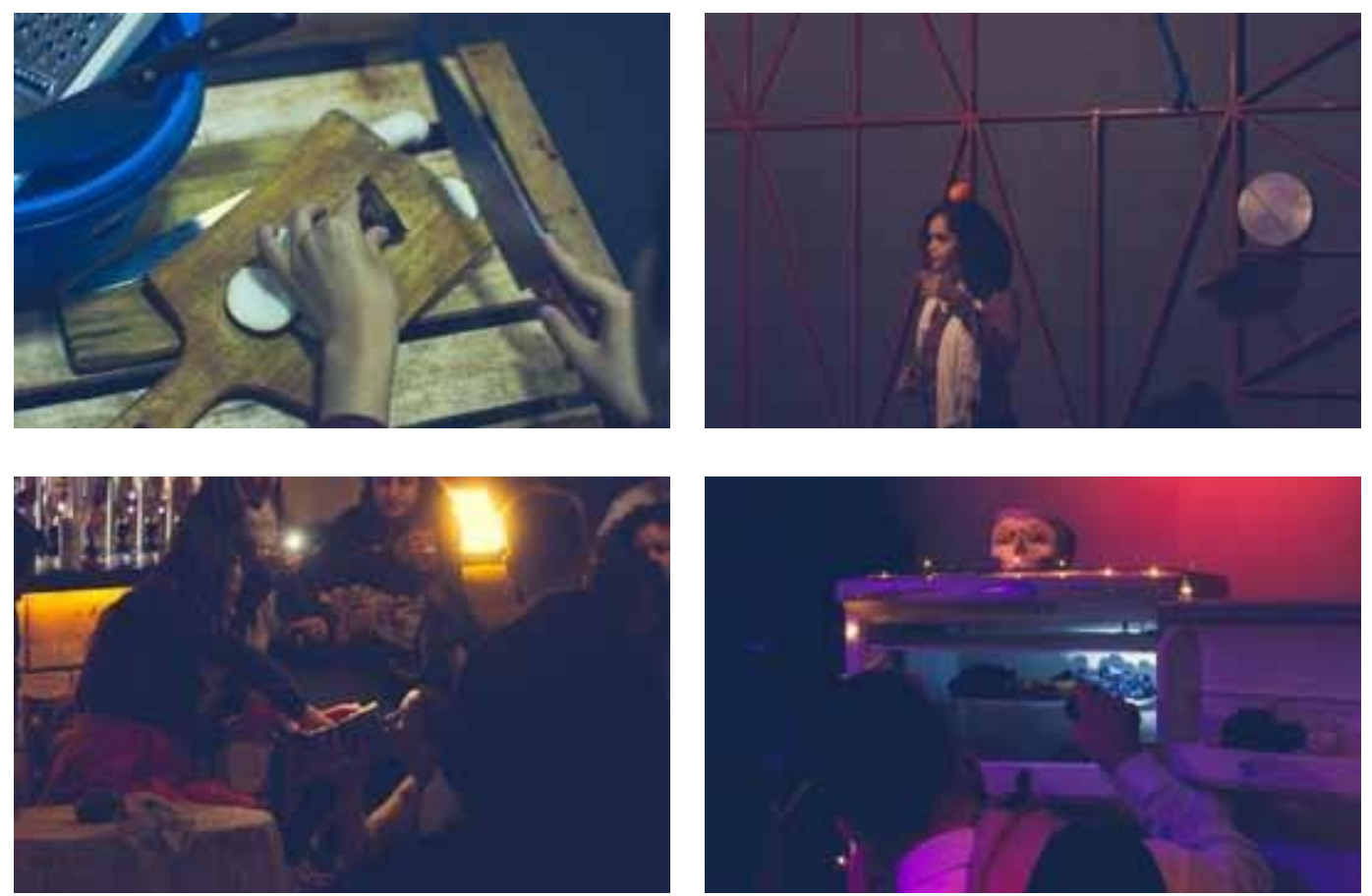

Figuras 7 a 10 - Gestos do cozinhar: extra/ordinário poético. Ocupação Teatro Bar, no Canteiro Central, Setor Comercial Sul de Brasília/DF, 2019. Fotos de Humberto Araújo

São proposições de abrir espaço para materializações coreográficas mais atentas às trocas que se estabelecem entre artistas, assim como entre artistas e espectadores (os quais proponho a também chamar de criadores) por meio de estruturas e sistemas coreográficos que amparem a escuta e a autonomia no que diz respeito à composição coreográfica. Na Poética do Convite, interessa entender que as escolhas são escolas. É sobre olhar para os encontros entre as pessoas como potências coreográficas. É convidar a nos perguntarmos como a gente se relaciona e se interessa junto, a fim de colaborar (compartilhar elaborações) a partir da nossa formação, história de vida, memórias e modos de ver/pensar/fazer o mundo. É sobre criação e formação dando-se sempre na experiência do encontro.

A cada nova configuração para sua existência, essa obra aberta nos tem permitido ampliar a prática do convite enquanto uma poética que evidencia a necessidade de constantemente repensar nossas éticas de trabalho. Como uma arte relacional, declara-se viva e jamais contida por uma receita fechada. A noção de ética, nesse sentido, é confrontada pela própria ação de se relacionar. Quem pode dizer o que pode, ou quando pode, senão a própria relação? Assim, por exemplo, temos que lidar com a escuta atenta para percebermos (até) 
quando um modo de operar (ainda) nutre determinado contexto relacional. Ana Carolina Mundim (2015) sugere que pensar a coreografia enquanto convite é, entre outras, a possibilidade de convidar "para olharmos o mundo com mais afeto e poesia, para causarmos mais encontros, para fazermos pequenas trans/formações (...) atrelar a lógica à percepção intuitiva" (2015, p. 45).

Olhar, perceber, viver em afeto. Afetar, ser afetada. Conectadas com nossos mínimos gestos, des/aprendemos diariamente a re/conhecer os interesses pessoais e coletivos de cada contexto e a cada contexto. Muitas vezes, é preciso perceber que cada contexto anuncia uma urgência. Estas urgências são dinâmicas e transitórias, por isso é tão importante abrirmo-nos para atualizar nossas pulsões: entre interesses e disponibilidades. Isto é, nesse contexto configurado, o que se anuncia desejoso? E o que se anuncia disponível? Nem sempre o que desejo é o que está disponível. Às vezes o que está disponível não é exatamente o que desejo. E o exercício de des/aprendizagem está aí: na habilidade de deslocar meus interesses e disponibilidades, transitar entre o que move e o que co/ move. Por vezes, coincidem-se desejos e disponibilidades e, quando isso acontece, estamos atentas para vivê-las.

Para que essas práticas se sustentem, tem sido necessária a prática da conversa nas mais diversas etapas dos processos. Dialogamos desde o início e muitas vezes é exigido que esse diálogo aconteça para além da fala: é sobre aprender a escutar com as ações, colocar-se de corpo todo e exercitar negociações e conversas pelas diversas vias que os tempos e espaços compartilhados nos demandam. Tem isso: na Poética do Convite precisamos entender o diálogo como uma característica que permeia toda e cada etapa do processo. $\mathrm{O}$ diálogo se dá na fala, mas se dá principalmente na escuta, na proposição e na compra da ideia do outro. O diálogo é motor em todas as instâncias de estruturação do pensamento coreográfico quando nos ajuntamos.

Como um modo de sintonizar nossa escuta, no entanto, temos exercitado uma prática posterior a cada Diaita. Utilizamos a conversa a partir do procedimento da "valoração", inspirada nos Ciclos RSVP7 de Anna Halprin, coreógrafa norte-americana. A valoração é o momento em que ecoamos percepções e traçamos escolhas de nossas experiências pessoais em cada prática vivenciada. Traduzir em palavras percepções das experiências de cada participante em tor- 
no de um mesmo acontecimento, ecoando aparições sincopadas de cantos de experiência, como metaforiza Larossa (2014, p. 10). É por meio dessas valorações que assentamos reflexões que as práticas suscitam e podemos, assim, realizar tomadas de decisão mais coletivas, ou ao menos mais consonantes com as autonomias plurais e diversas, encontrando chãos comuns entre nós. Nessa ética de trabalho, cada pequena jornada tem se tornado a possibilidade de uma jornada autônoma de des/aprendizagem. Autonomia pessoal. Autonomia coletiva.

Sendo assim, finalizo esse escrito com alguns convites que permanecem desejosos:

- a nós, diretoras e coreógrafas, a refletir que nossos processos de criação são espaços de formação. Perguntemo-nos, então, o que temos in/formado, re/ formado, trans/formado entre as práticas e os discursos que operamos;

- a nós, dançarinas e criadoras, a ocuparmos nossos espaços de responsabilidade, escolha e trans/formação pessoal e coletiva em constante busca do alinhamento de nossos interesses aos interesses daqueles com quem trabalhamos e/ou nos relacionamos;

- a nós, educadoras, a problematizar nossos planos e verdades rumo à trans/ formação por meio de pensamentos mais flexíveis e disponíveis a saber não saber;

- a nós, des/aprendizes, a tomarmos para nós a responsabilidade da aprendizagem autônoma e diária, colocando em risco a exposição de nossas ideias e validando nossas curiosidades como conteúdos de trans/formação. Convido-nos à trans/formação. 


\section{Referências}

FABIÃO, Eleonora. Performance e teatro: poéticas e políticas da cena contemporânea. Sala Preta, São Paulo: PPG-Artes Cênicas/USP, n. 8, 2008, p. 235-246. Disponível em: <http://www.revistas.usp.br/salapreta/article/view/57373/60355>. Acesso em: 18 jul. 2019.

FERNANDES, Silvia. Teatralidade e performatividade na cena contemporânea. Repertório. Salvador: PPG-Artes Cênicas/UFBA, v. 16, 2011, p. 11-23. Disponível em: <https://portalseer.ufba.br/index.php/ revteatro/article/view/5391>. Acesso em 18 jul. 2019.

FOLEY, Cindy. Teaching art or teaching to think like an artist? TEDXColumbus., 2014. Disponível em: < https://www.youtube.com/ watch?v=ZcFRfJb2ONk>. Acesso em 15 nov. 2018.

GARCÉS, Marina. Un mundo común. Editor digital: marianico_elcorto. ePub base r1.1, 2013. Disponível em: <epubgratis.net>. Acesso em: 10 jun. 2019.

LAROSSA, Jorge. Tremores: escritos sobre experiência. Tradução: Cristina Antunes, João Wanderley Geraldi. 1a ed. Belo Horizonte: Autêntica Editora, 2014.

MANNING, Erin. The minor gesture. Durham: Duke University Press, 2016.

MARQUES, Isabel A. Linguagem da dança arte e ensino:. 1a ed. São Paulo: Digitexto, 2010.

MUNDIM, Ana Carolina. O que é coreografia? In: A cena em foco: artes coreográficas em tempos líquidos / Marcia ALMEIDA (org.); Susi Weber ... [et al.]. Brasília: Editora IFB, 2015.

TRIDAPALLI, Gladistoni. Aprender investigando: a educação em dança é criação compartilhada. Salvador, 2008. Dissertação (Mestrado em Dança) - Programa de Pós- Graduação em Dança, Escola de Dança, Universidade Federal da Bahia, Salvador, 2008. 
VILLAR, Fernando Pinheiro. Algo mais sobre performance, teatro e teatro performance - sangrando o "performão". In: BEIGUI, A., BRAGA, B. (Org). Treinamentos e modos de existência. Natal: EDUFRN, 2013. p. 127-162. 